\title{
Clipping as re-treatment strategy after treatment of a cerebral aneurysm with the Woven EndoBridge embolization device: case report
}

\author{
Gregor Durner, MD, ${ }^{1}$ Yigit Özpeynirci, MD, ${ }^{2}$ Bernd Schmitz, MD, ${ }^{2}$ Christian Rainer Wirtz, MD, ${ }^{1}$ \\ Ralph König, MD, PhD, ${ }^{1}$ and Andrej Pala, MD'1
}

Departments of ${ }^{1}$ Neurosurgery and ${ }^{2}$ Neuroradiology, University of Ulm, Günzburg, Germany

Recently, treatment of cerebral aneurysms with the Woven EndoBridge (WEB) device has become an established endovascular strategy. However, over time, neurosurgeons and neuroradiologists will be confronted with the challenge of how to treat aneurysm recanalization. The authors report the case of a 49 -year-old woman who underwent re-treatment with clipping after the recanalization of a $4 \times 3-\mathrm{mm}$ anterior communicating artery aneurysm that had previously been treated using a $4 \times 3$ WEB device. In contrast to the authors' prior experiences with clipping of previously coiled aneurysms, the WEB device was found to have a responsive softness during clip placement, and the aneurysm was more maneuverable. Moreover, evaluation with indocyanine green angiography was easy to perform because of the transparent mesh of the WEB device. No profound scarring or WEB protrusion was noted during surgery, making the procedure easier and less dangerous with regard to additional complications. The authors suggest that re-treatment via clipping should be considered in select cases of aneurysm recurrence after treatment with an intraaneurysmal flow diverter.

https://thejns.org/doi/abs/10.3171/2017.10.JNS171528

KEY WORDS Woven EndoBridge device; WEB; re-treatment; cerebral aneurysm; clipping; coiling; vascular disorders

$\mathrm{O}$ VER the past few decades, great advances have been made in the treatment of cerebral aneurysms. In this field, coiling has become a common alternative to surgical clipping..$^{10}$ The Woven EndoBridge (WEB; Sequent Medical) device is one of the latest innovations added to the armamentarium of endovascular treatment (EVT) devices, especially for wide-neck bifurcation aneurysms. The WEB device was introduced in $2011,5,7$ and recent studies have confirmed its feasibility and safety. ${ }^{6,13}$ Occlusion rates up to $81.1 \%$ have been reported in shortterm studies. ${ }^{911}$ In a long-term study with a median followup of 27.4 months, Pierot et al. showed satisfying results and occlusion rates of $68.4 \% .^{12}$ Nevertheless, the risk for incomplete obliteration or recurrence is higher with the WEB device than with surgical clipping, inevitably resulting in more re-treatments in the future. Treatment strategies for recanalization associated with WEB devices have not yet been approved. To our knowledge, we present the first case of surgical clipping after previous intraaneurysmal flow diverter embolization with the WEB device.

\section{Case Report}

A 49-year-old woman presented with a history of 2 incidental aneurysms located at the anterior communicating artery $(\mathrm{ACoA} ; 4 \times 3 \mathrm{~mm})$ and the basilar bifurcation. The patient had arterial hypertension, had abused nicotine, and had a family history that was positive for subarachnoid hemorrhage. Because of their wide-neck configuration, both aneurysms were treated using a $4 \times 3-\mathrm{mm}$ WEB device within 3 months.

Treatment of the basilar tip aneurysm was performed in June 2015 after the patient received loading doses of aspirin and clopidogrel 1 week prior to intervention. After

ABBREVIATIONS ACOA = anterior communicating artery; DSA = digital subtraction angiography; $E V T$ = endovascular treatment; ICG = indocyanine green; WEB = Woven EndoBridge.

SUBMITTED June 25, 2017. ACCEPTED October 2, 2017.

INCLUDE WHEN CITING Published online March 23, 2018; DOI: 10.3171/2017.10.JNS171528. 


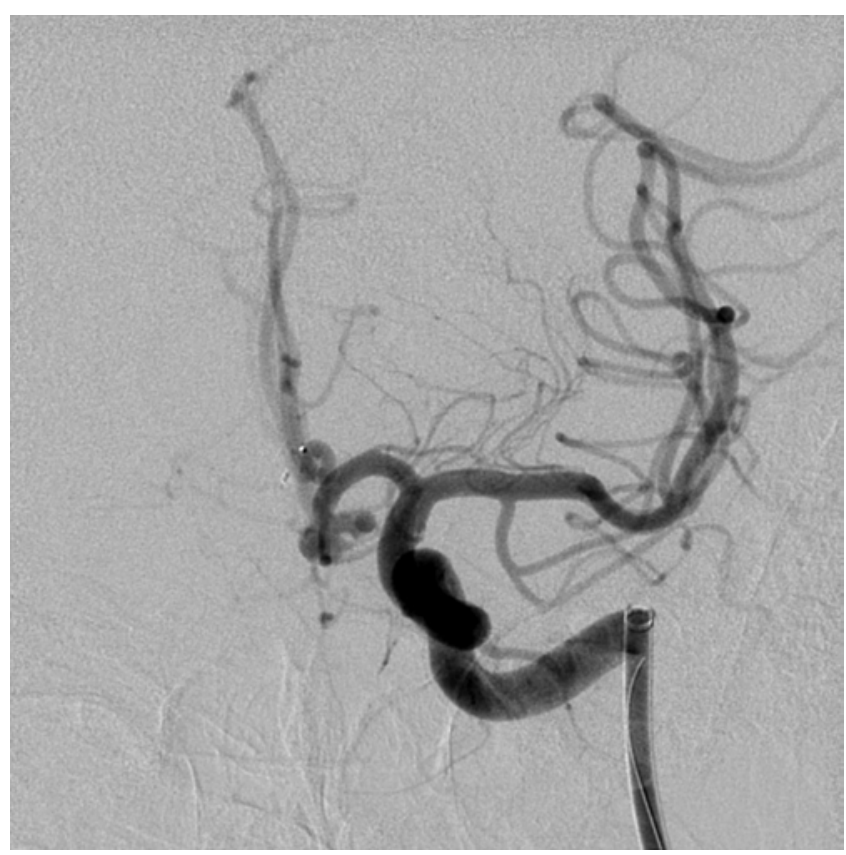

FIG. 1. Digital subtraction angiogram of the left carotid artery showing signs of recanalization in the $\mathrm{ACOA}$ after primary treatment with a WEB device.

treatment, aspirin was recommended for 3 more months, and the clopidogrel was discontinued. Treatment of the 4 $\times 3-\mathrm{mm}$-diameter, anteriorly and caudally oriented ACoA aneurysm was performed 3 months later following the same scheme. Platelet inhibition with aspirin was continued for 3 more months.

No neurological deficits occurred after the EVT with the WEB device. At the first follow-up, 6 months after the intervention, digital subtraction angiography (DSA) revealed contrast agent inside and around the device (Bicêtre Occlusion Scale Score 1+3; Fig. 1). ${ }^{3}$ The basilar aneurysm showed no signs of recanalization. After the case was presented at our interdisciplinary neurovascular team conference, re-treatment with surgical clipping was recommended.

The wide-neck configuration of the aneurysm would require stent-assisted EVT; the need for lifelong platelet inhibition was likely, with the possible risk for unexpected bleeding complications. Considering the multiple risk factors and the patient's young age, re-treatment with microsurgical clipping was eventually recommended.

The procedure was performed by one of the senior authors (R.K.) via a right supraorbital approach. The aneurysm was dissected, thus avoiding the use of permanent retraction. Only minimal arachnoid scarring around the aneurysm was apparent. The mesh of the WEB device was detected through the thin, transparent aneurysm wall (Fig. 2). As noted on angiography, the right $A_{1}$ segment was dominant, and the aneurysm originated from the right $\mathrm{A}_{1}-\mathrm{A}_{2}$ angle. There was no protrusion of the embolization device into the subarachnoid space, a phenomenon frequently detected in previously coiled aneurysms (Fig. 2). Because of its low radial force, the WEB device was easily compressible inside the aneurysm. Finally, the aneurysm was occluded using a 7-mm straight clip (Lasic Aneurysm Clip System, Peter Lasic GmbH). Intraoperative indocyanine green (ICG) angiography was performed, and the clip had to be repositioned twice to achieve complete aneurysm occlusion (Fig. 3). Compared with previously coiled aneurysms, intraluminal coils may impede assessment of residual aneurysm filling or residual aneurysm neck. However, because of the transparent mesh of the WEB device, ICG angiography findings were easy to interpret in this case. ICG confirmed patency of both $\mathrm{A}_{2}$ segments and Heubner arteries (Fig. 3) as well as complete aneurysm occlusion.

The patient's postoperative course was uneventful, and no neurological deficits occurred after surgery. Complete aneurysm occlusion was confirmed by DSA. Six days after surgery, the patient was discharged home. On follow-
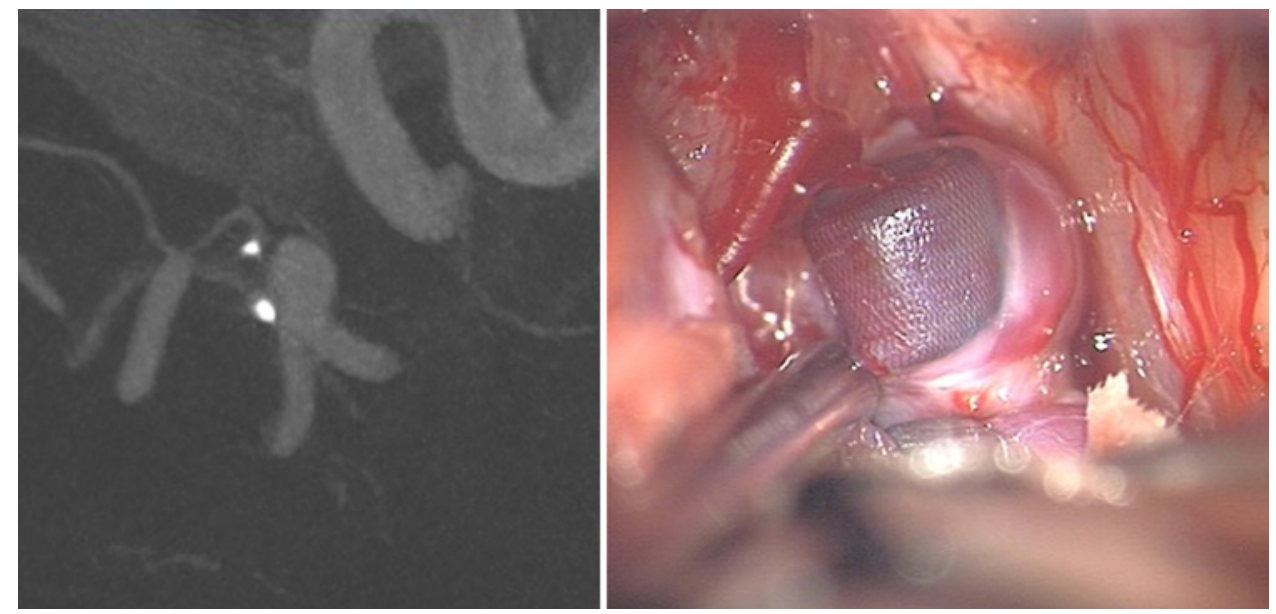

FIG. 2. CT angiogram (left) and intraoperative photograph (right) of a recanalized ACoA. Little scarring and no signs of WEB device extrusion can be seen. Figure is available in color online only. 

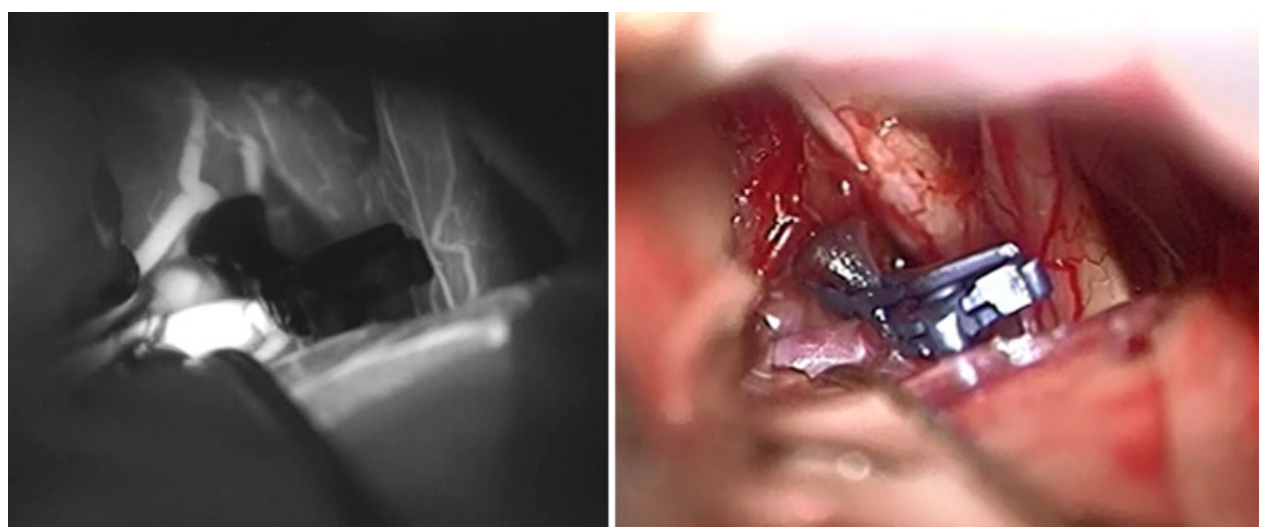

FIG. 3. ICG angiogram (left) and intraoperative photograph (right) of the ACOA after re-treatment using a 7-mm clip, confirming aneurysm occlusion. Figure is available in color online only.

up, no late complications were reported. Follow-up imaging with CT angiography showed no recanalization of the ACoA aneurysm.

\section{Discussion}

The WEB device has become a new player in the EVT of cerebral aneurysms. The focus of this system is wideneck bifurcation aneurysms that are difficult to occlude with coiling. ${ }^{1}$ Even if EVT is a common and safe therapy, it is associated with higher recanalization rates compared with microsurgical clipping., ${ }^{2,14}$ The few available longterm results of WEB treatment showed complete occlusion in $68.4 \%$ and adequate occlusion in $84.2 \%$ after 27.9 \pm 13.7 months. ${ }^{12}$ An increased recanalization rate should be assumed, and regular follow-ups should occur. Strategies for re-treatment are not clearly defined and need to be discussed and evaluated by further studies.

As for surgical clipping, Daou et al. reported an occlusion rate of $97.3 \%$ after clipping of previously coiled aneurysms. Additionally, $90 \%$ of patients had a good clinical outcome with modified Rankin Scale scores of 0-2.,15 Surgical clipping is a permanent solution in almost all cases, and, if aneurysm occlusion is verified by DSA, further recurrence is very rare. ${ }^{14}$

Wallner et al. reported a positive experience with the case of regrowth of a middle cerebral artery aneurysm that was initially occluded with a WEB device, recurred, and was re-treated with coiling. ${ }^{16}$ Re-treatment with coils, however, might result in coil dislocation or the use of endovascular stents that require mostly lifelong oral platelet inhibition.

To the best of our knowledge, there are no reports of clipping of cerebral aneurysms after initial treatment with a WEB device. As for coiled aneurysms considered for surgical re-treatment due to recanalization, we have reported our first experience in a small series of 10 patients and showed that the procedure is feasible with good results when eligible patients are selected carefully by an interdisciplinary vascular team. ${ }^{8}$ Similarly, in their cohort of 111 patients, Daou et al. reported complete occlusion rates of $97.3 \%$ after re-treatment by clipping, indicating the safety and effectiveness of clipping as the re-treatment method after previous coiling. ${ }^{4}$ Even if the procedure is safe and leads to high occlusion rates without increased complications, some aspects need to be considered before surgery. Coil extraction might be necessary in some cases to achieve complete aneurysm occlusion or better anatomical preparation due to profound scarring. However, coil extraction seems to be associated with a higher risk for stroke, which might result in a severe neurological deficit. ${ }^{4}$ The risk of WEB extrusion seems to be less likely due to the nature of this device. Additionally, we found no scarring while preparing the aneurysm for clipping due to the soft nature of the WEB. Its compressibility allowed simple clip positioning without the need for extraction of the WEB device. Furthermore, intraoperative ICG angiography was very valuable in our case. The assessment of intraluminal patency and aneurysm remnants might be more difficult in the case of a previously coiled aneurysm since coils can obscure aneurysm filling and impede the assessment of intraluminal blood flow. Because of the transparency of the WEB device, ICG angiography findings could be easily interpreted, thus providing an excellent evaluation of the treatment after clip positioning in our case. However, aneurysm recurrences with larger atherosclerotic plaques can pose difficulties during ICG angiography evaluation. Based on the nature of WEB devices, this concern seems to be less relevant than during clipping of previously coiled aneurysms.

\section{Conclusions}

Clipping of previously coiled aneurysms has become a common procedure over the past few years, resulting in high occlusion rates and good clinical outcome. With new endovascular devices, re-treatment strategies for recurrent aneurysms need to be established. Our first experience with clipping to treat recanalization of an aneurysm initially treated with a WEB device is similar in terms of feasibility and safety to our experience with re-treating previously coiled aneurysms. We also experienced easier handling and clip placement in this case, and the aneurysm was more maneuverable. Moreover, ICG angiogra- 
phy evaluation was easy because of the transparent mesh of the WEB. No profound scarring or WEB protrusion was noted during the surgery, making the procedure simpler and less dangerous with regard to additional complications. Further studies will have to provide more data and statistical analysis.

\section{References}

1. Armoiry X, Turjman F, Hartmann DJ, Sivan-Hoffmann R, Riva R, Labeyrie PE, et al: Endovascular treatment of intracranial aneurysms with the WEB device: a systematic review of clinical outcomes. AJNR Am J Neuroradiol 37:868-872, 2016

2. Campi A, Ramzi N, Molyneux AJ, Summers PE, Kerr RSC, Sneade M, et al: Retreatment of ruptured cerebral aneurysms in patients randomized by coiling or clipping in the International Subarachnoid Aneurysm Trial (ISAT). Stroke 38:1538-1544, 2007

3. Caroff J, Mihalea C, Tuilier T, Barreau X, Cognard C, Desal $\mathrm{H}$, et al: Occlusion assessment of intracranial aneurysms treated with the WEB device. Neuroradiology 58:887-891, 2016

4. Daou B, Chalouhi N, Starke RM, Barros G, Ya'qoub L, Do J, et al: Clipping of previously coiled cerebral aneurysms: efficacy, safety, and predictors in a cohort of 111 patients. J Neurosurg 125:1337-1343, 2016

5. Ding YH, Lewis DA, Kadirvel R, Dai D, Kallmes DF: The Woven EndoBridge: a new aneurysm occlusion device. AJNR Am J Neuroradiol 32:607-611, 2011

6. Gherasim DN, Gory B, Sivan-Hoffmann R, Pierot L, Raoult $\mathrm{H}$, Gauvrit JY, et al: Endovascular treatment of wide-neck anterior communicating artery aneurysms using WEB-DL and WEB-SL: short-term results in a multicenter study. AJNR Am J Neuroradiol 36:1150-1154, 2015

7. Klisch J, Sychra V, Strasilla C, Liebig T, Fiorella D: The Woven EndoBridge cerebral aneurysm embolization device (WEB II): initial clinical experience. Neuroradiology 53:599-607, 2011

8. König RW, Kretschmer T, Antoniadis G, Seitz K, Braun V, Richter HP, et al: Neurosurgical management of previously coiled recurrent intracranial aneurysms. Zentralbl Neurochir 68:8-13, 2007

9. Lubicz B, Klisch J, Gauvrit JY, Szikora I, Leonardi M, Liebig T, et al: WEB-DL endovascular treatment of wide-neck bifurcation aneurysms: short- and midterm results in a European study. AJNR Am J Neuroradiol 35:432-438, 2014

10. Mine B, Goutte A, Brisbois D, Lubicz B: Endovascular treat- ment of intracranial aneurysms with the Woven EndoBridge device: mid term and long term results. J NeuroIntervent Surg [epub ahead of print], 2017

11. Pierot L, Costalat V, Moret J, Szikora I, Klisch J, Herbreteau D, et al: Safety and efficacy of aneurysm treatment with WEB: results of the WEBCAST study. J Neurosurg 124:1250-1256, 2016

12. Pierot L, Klisch J, Liebig T, Gauvrit JY, Leonardi M, Nuzzi NP, et al: WEB-DL endovascular treatment of wide-neck bifurcation aneurysms: long-term results in a European series. AJNR Am J Neuroradiol 36:2314-2319, 2015

13. Pierot L, Moret J, Turjman F, Herbreteau D, Raoult H, Barreau X, et al: WEB treatment of intracranial aneurysms: feasibility, complications, and 1-month safety results with the WEB DL and WEB SL/SLS in the French Observatory. AJNR Am J Neuroradiol 36:922-927, 2015

14. Raja PV, Huang J, Germanwala AV, Gailloud P, Murphy KPJ, Tamargo RJ: Microsurgical clipping and endovascular coiling of intracranial aneurysms: a critical review of the literature. Neurosurgery 62:1187-1203, 2008

15. Rankin J: Cerebral vascular accidents in patients over the age of 60. I. General considerations. Scott Med J 2:127-136, 1957

16. Wallner AK, Broussalis E, Hauser T, Trinka E, Killer-Oberpfalzer M: Coiling after treatment with the woven EndoBridge cerebral aneurysm embolization device. A case report. Interv Neuroradiol 18:208-212, 2012

\section{Disclosures}

The authors report no conflict of interest concerning the materials or methods used in this study or the findings specified in this paper.

\section{Author Contributions}

Conception and design: König. Acquisition of data: König. Analysis and interpretation of data: Durner, Özpeynirci, Schmitz, Pala. Drafting the article: Durner, Pala. Critically revising the article: Özpeynirci, Schmitz, Pala. Reviewed submitted version of manuscript: Durner. Approved the final version of the manuscript on behalf of all authors: Durner. Administrative/technical/material support: König. Study supervision: Wirtz, König.

\section{Correspondence}

Gregor Durner: University of Ulm, Günzburg, Germany. gregor. durner@googlemail.com. 